\title{
Population Dynamics in Artificial Agent Societies: A Review
}

\author{
Harjot Kaur ${ }^{1}$, Avneet Kaur ${ }^{2}$ \\ Department of Computer Science and Engineering, GNDU Regional Campus, Gurdaspur, Punjab, India ${ }^{1,2}$
}

\begin{abstract}
This paper "Population Dynamics in Artificial Agent Society" broadly covers the change of population in human and agent societies. There are certain causes like Natality, Mortality, and Migration that are responsible for such a change. These causes are referred to as key elements of population dynamics. Moreover a Demographic view of population is provided. To simulate the human society agent-based modeling is implemented in object oriented programming language that society is called artificial agent society. Through this paper introduction of new agent ,death of agent in society and migration of agents are discussed. At last the metrics for measuring number of agents migrating to and from society, and metrics for measuring agent-based society are discussed.
\end{abstract}

Keywords: fertility, mortality, migration, metrics.

\section{INTRODUCTION}

A population is a group of individuals (all members of a single species) who live together in the same habitat and are likely to interbreed [6].

The "dynamics" of populations is termed asthe ways in which population grow and shrink as the time is passed [10]. The population has two kinds of input -- birth (natality/fertility) and immigration. And each population has the same two outputs -- death (mortality) and emigration.

If the inputs are greater than the outputs, the population will grow. If the outputs are higher than the inputs, it will shrink. If the two are in balance, the population size will not change. This change in Population is called Population dynamics

The Dictionary meaning of Population Dynamics is [8]:

"A branch of knowledge concerned with the sizes of populations and the factors involved in their maintenance, decline, or expansion"

\section{A. Population Dynamics in Human Societies}

Population Dynamics in human societies deals with shortterm and long-term changes in the size and age composition of human populationand the biological and environmental processes influencing those changes.

Human population trends are important because they help to determine how rising population put increasing demandson natural resources such as land, water, and energy supplies [7]. Human Population Dynamics comprises of changes in population growth, migration, urbanization, population density, and age structure [4]. Birth (natality/fertility), death (mortality), migration (including immigration, and emigration) are the primary ecological events that cause change in population that are explained latter in this paper. There are some secondary ecological events that influence the population [6]. These are:

Density-Independent Factors: - Thesefactors include weather or climate conditions that affect all individuals equally. Favorable climate conditions can effect population positively as much as the unfavorable conditions can effect negatively on population.

- Density-Dependent Factors: -density dependent factors are those factors that change in severity as population increases or decreases. Diseases are the common example of density dependent factors.

Human Population dynamics have a major impact on human rights, equality, environmental sustainability, peace and security, social development [4]. Individual's family and community condition act as consequences of change in population. It emerges as ability of individuals to enhance their status and dignity.

B. Population Dynamics in Artificial Agent Society Agent-based computer modeling techniques are applied to study thehuman social phenomena, including trade, migration, group formation,combat, interaction with an environment, transmission of culture, propagationof disease, and population dynamics [3].Agent based computer modeling was firstly applied to social science by Thomas Schelling in his papers "Models of Segregation"[1969], "On the Ecology of Micromotives"[ 1971a], and "Dynamic Models of Segregation"[ 1971b]and later in the book Micromotivesand Macrobehavior[ 1978]. Schelling anticipated social complexity, economic evolution on agent-based modeling. He devised a spatially distributed model of composition of neighbors that include agents as the people of artificial agent society. The first introduction of agent-based simulation was in the form of game of life by Cambridge mathematician John Conway. This invention was enhanced and applied to arena of social simulation by J.Epstein and R.Axtell in their book "Growing Artificial Societies".

Epstein and Axtell implementation came to be known as the Sugarscape Model. Sugarscape refers to the siliconbased society that they created. It included the agents, the rules governing the interaction of the agents with each 


\section{International Journal of Advanced Research in Computer and Communication Engineering} Vol. 4, Issue 3, March 2015

other and environment (2-D grid). Agents or citizens move in this environment gathering food, mating with suitable partners, bearing offspring's, bartering goods with other agents, migration, dying and leaving an inheritance for their survivors. So population dynamics in terms of artificial agent society is change in the population of agents in their society. The causes behind the change are the Natality, Mortality and migration.

\section{A. Demographic View}

Demography is defined as scientific study of human population.It is the study of population structure and processes. In 1855 Achille Guillard defined Demography in his own book as:

"The mathematical knowledge of populations, their general movements, and their physical, civil, intellectual and moral state"

The prime forces behind social and technological change are Population changes. As population size changes in an area-whetherit be growth or decline-adjustment is needed, and these adjustments provide alterations to the way society operates [2]. Demography is a force that moves simultaneously with every improvement in wellbeing that has been witnessed over the past few hundred years. A societal response is demanded in Demographic change, but different societies will respond differently,sometimes for the better, sometimes not. In Human Population there are several basic truths that apply to demographics of human society [7]:

- $\quad$ Everyone will be one year older after one year if he/she is alive the next year.

- $\quad$ Biologically age 15-49 are human child bearing age.

- Infants, Children, and adults over the age of 60 are more prone to human mortality. More over mortality is low at other parts of human life cycle.

Taking into consideration the above observations the population analyst can accurately estimate the society's population size, births, deaths, and age structure for next few years. Similarly there are some factors that decide agent's demography that are discussed in later section. When a population is moving from high mortality and fertility to low mortality and fertility then that is called as Demographic Transition[4] .Fertility, Migration, and Mortality are the determinants of Demographic Change [7].

\section{KEY ELEMENTS OF POPULATION DYNAMICS}

Fertility (Birth), Mortality (Death), Migration drives the population changes and influence age structure and population distribution and population density [4]. These are also called determinants of demographic change.

- Fertility: -It is expressed as total fertility rate. In human population it is the number of births that can be expected to occur to a typical woman in a given society during her childbearing years [7].

- Mortality: - Mortality is the second major variable that shapes the population trend. In case of
Human's there are certain age groups that have high death rates i.e. Infants, young children, elders. To estimate longevity in a society, life expectancy is calculated [7]. Life expectancy is the age that a new born baby would on average live up to.

- Migration: - Migration is the third element that causes the demographic change. It includes geographical population shifting within nation and across borders [7]. On positive level migration can provide the receiving society with needed labor. But on negative side,it drains the valuable talent from destination society.

\section{INTRODUCTION OF A NEW AGENT INTO THE SOCIETY}

Sugarscape is a spatial distribution of "sugar" a generalized resource that agent must eat to survive. At any point on grid, there is sugar level and sugar capacity, the capacity being maximum value the sugar level can take at any point. Agent reproduction and cloning introduce new agents into the society.

\section{A. Agent reproduction}

For introduction of new agent into society agents must engage in sexual reproduction with neighbors. But for reproduction agents must be fertile. For agent to be fertile firstly, it must be of child bearing age. Secondly, children born must have initial endowment of sugar metabolism and level of visionotherwise they will instantly die.

It is required that parents must give their children some initial endowment for their survival. Each newborn endowment is sum of the contribution of mother and father. Dad contributes an equal to one half of whatever his initial endowment had been, and likewise for mom. To be able to reproduce, the agents must have collected at least the amount of sugar with which they were endowed at birth. Agents meeting these age and wealth requirements are defined as "fertile". Each fertile agent executes sex rule, which is as follows:-

Select a neighbor agent at random.

If the agent is fertile and of opposite sex and at least one of the agents has an empty neighboring site (for baby), then a child is born.

- $\quad$ Repeat for all neighbors.

The agent will mate with each of neighboring agent, if all of four agents are viable partners. The sex of child born is random. The child's genetic makeup that includes metabolism, vision, and maximum age depends on parents. Imagine one parent to be of type $(\mathrm{m}, \mathrm{v})$ while the other parent is genetically $(\mathrm{M}, \mathrm{V})$, then there are four genotype for their child: $(\mathrm{m}, \mathrm{v}),(\mathrm{m}, \mathrm{V}),(\mathrm{M}, \mathrm{v}),(\mathrm{M}, \mathrm{V})[3]$.

The agents produced by reproduction are heterogeneous from the perspective of their environment that includes their position and sugar accumulation. They are homogeneous with regard to their behavioral rules.

The populations of agents have following characteristics:

- for both men and women, childbearing begins between the ages of 12 and 15 ;

- for women, childbearing terminates between the ages of 40 and 50; 
- for men, childbearing terminates between the ages of 50 and 60 ;

- $\quad$ for both men and women, the age of natural death is between 60and 100;

- Members of the initial population have initial endowments in therange 50 to 100 sugar units.

B. $\quad$ Cloning

Agents are the learning agents that autonomously improve both knowledge and performance through learning strategies. Evolutionary Agents (EVA) is an approach that is based on a cloning process. EVA is similar to the biologic asexualreproductive processes generating clones that initially are the exact copies oftheir parents.EVA approach helps users to substitute unsatisfactory agents with other agents having good reputation [1]. It allows the best agent to emerge over less productive agents. This approach is user-centric requiring a user's request to clone an agent. This cloning slowly generates modifications in agent population.

\section{DEATH OF AN AGENT IN THE SOCIETY}

Every agent in the society has genetic endowment consisting of a sugar metabolism and a level of vision as explained earlier. Metabolism of sugar is the amount of sugar burned by agent per step. An agent with vision v can see $\mathrm{v}$ units in the four principal lattice directions: north, south, east, and west. If at anytime the agent's sugar falls to zero or below then agent is unable to accumulate enough sugar to satisfy its metabolic demandsthen that agent starve to death and it is removed fromthe sugarscape [3]. If an agent does not starve it lives forever. When an agent has high metabolism rate but low vision then that agent has hard life ultimately leading to death of agent.

Pollution is another cause of agent death. Pollution can be produced by agent movement, agent gathering activities, agent sugar consumption and sugar grow back. Pollutants degrade the environment and reduce the welfare of agents. Pollutants can enter the body of agent and make them sick by degrading their vision or increasing their metabolism. Pollution can be devalued by modifying the agent movement to site with maximum sugar levels and low pollution levels.Pollution is transported from one site to another through diffusion. So when pollution occurs agents are moved to areas having no pollution from sugar production. In pristine area agents eat from their personal accumulations but they produce pollution in this area also through consumption. Agents start dying in this area due to little food and moreover due to pollution.

Disease transmission is another reason for agent death. Disease is transmitted from infected agent to its neighboring agent. The rule behind disease transmission is:

"For each neighbor, a disease that currently afflicts the agent is selected at random and given to neighbor"

Different diseases have different effects. Some diseases reduce vision of agent when agent is infected while other can interrupt its normal sexual activity [3]. A diseased agent has metabolism increased to some amount. These changes effect the lifespan of agents as explained earlier that agents with high metabolism and low vision have hard life. The sick agent will have behavior different than that of healthy agent. In case of multiple diseases, one disease is selected at random and passed on to neighbor. Each agent is born with an immune system that is inherited from parentsto combat against diseases. Every time when an agent is infected by some disease its immune system learns that disease and provides immunity to agent from that disease.

Diseases are transported from one site to another through diffusion.

\section{MIGRATION OF AGENTS IN THE SOCIETY}

In human society movement of people to new area or country in order to find work or better living condition is termed as migration. It may be defined as temporary or permanent move of individuals or group of people from one geographic location to another for various reasons ranging from better employment possibilities to exile. While talking in terms of artificial agent societies, movement of agents in between societies or to new society from time-to-time for various reasons ranging from societal, economic, social or personal reasons is termed as Agent migration. Migration is considered as complex, dynamic and selective process. It is integral part of broader process of development of societies, which in turn helps in growth of societies. Internal (related to agent), external (societal) issues related to migration are called migration dynamics.

In agent migration, the agent that migrates into new society is termed as immigrant agent, whilethe agent that is leaving a society is termed as em-migrant agent. The society of origin from which agent starts its migration is called migration source or sending source. The destination society to which agent migrates is called as migration sink or receiving society.

\section{A.Metrics for measuring migration}

The number of agents migrating from one society to another can be measured using direct methods and indirect methods.

1. Direct methods of measuring migration

Direct method of measuring migration is used to measure in-migration rate, out-migration rate, net or crude migration rate, gross or total migration rate, migration effectiveness, and migration ratio [2].

a. In-migration rate (IMigR)

The total number of agents that movedinto specific societyto total population of the society during specific time period multiplied by some constant 100 or 1000 [2].

$$
\mathrm{IMigR}=(\mathrm{IM} / \mathrm{P}) * 1000
$$

Where IMigR = In-migration rate

$\mathrm{IM}=$ the number of in-migrants to a specific society

$\mathrm{P}=$ the total population of the society

\section{b. Out-migration rate (OMigR)}

The total number of agents that moved out to a specific society to total population of society during specific time period multiplied by some constant 100 or 1000 [2].

$\mathrm{OMigR}=(\mathrm{OM} / \mathrm{P}) * 1000$ 
Where OMigR= Out-migration rate

$\mathrm{OM}=$ the number of out-migrants to a specific society

$\mathrm{P}=$ the total population of the society.

\section{c. Net or crude migration rate (CNMigR)}

The Net or crude migration is the difference between those who move in and those who moved out. If those numbers are same, then the net migration is zero. If there are more in-migrants than out-migrants, the net migration is positive; and if the out-migrants exceeds the in-migrants, the net migration is negative. The crude net migration rate(CNMigR) is thus the net number of migrants in a year per 1000 agents in a population, and it is the difference between the net in- and out- migration rates:

$$
\mathrm{CNMigR}=\mathrm{IMigR}-\mathrm{OmigR}
$$

\section{d. Gross or total migration rate (TMigR)}

Grossor total migration rate (TMigR) is sum of inmigration rate and out-migration rate:

$$
\text { TMigR = IMigR+OmigR }
$$

\section{e. $\quad$ Migration effectiveness $(E)$}

Migration measures how "effective". The total volume of migration is in redistribution of population. For example, if there were a total of 10 migrants in a region in a year and all 10 were in-migrants, the effectiveness of migration would be $10 / 10$, or 100 percent [2].

$$
\mathrm{E}=(\mathrm{CNMigR} / \mathrm{TMigR}) * 100
$$

\section{f. $\quad$ Migration ratio (MigRatio)}

This ratio is used to measure the contribution that migration makes to population growth by calculating the ratio of net migration to natural increase ( the difference between births and deaths) given by:

$$
\text { MigRatio }=(\text { NetMig/b-d }) * 1000
$$

\section{Indirect methods of measuring migration}

Indirect method is used to measure net intercensal migration. It is used to estimate net migration on basis of population count of an society at two successive census. The population increment between any two dates for any society or area is result of natural increase (births and deaths) and net migratory movement[9].There are two approaches to estimate : (a) vital statistical method (b) survival ratio method.

\section{a. $\quad$ Vital statistical method}

The estimate is obtained by subtracting the natural increase ( births and deaths ) from the total population change. The balancing equation used is:

$$
\text { Net } M=\left(p_{t+n}\right)-p_{t}-(b-d)
$$

Where Net $\mathrm{M}=$ is Net migration,

$\mathrm{P}_{\mathrm{t}}$ is the population at earlier census,

$\mathrm{P}_{\mathrm{t}+\mathrm{n}}$ is the population at later census,

$\mathrm{b}$ is the number of births that occurred to resident society during intercensal period, and

$\mathrm{d}$ is the number of deaths that occurred to residents of society during same period.

Thus, if two census are taken $\mathrm{n}$ years apart, the population aged $\mathrm{x}$ years at earlier census and surviving to later census will be $x+n$ years old. If the number of deaths in the intercensal period to persons of agent society who were $\mathrm{x}$ years of age at time of earlier census can be determined, then the net migration of persons in this age cohort can be obtained using balancing equation:

$$
\text { Net } M(x)=p_{x+n, t+n}-p_{x, t}+d(x)
$$

Where $\mathrm{M}(\mathrm{x})$ is the migration among agents who were aged $\mathrm{x}$ at earlier census, $\mathrm{p}_{\mathrm{x}+\mathrm{n}, \mathrm{t}+\mathrm{n}}$ is the population aged $\mathrm{x}+\mathrm{n}$ years at later census, $\mathrm{p}_{\mathrm{x}, \mathrm{t}}$ is the population aged $\mathrm{x}$ at earlier census, and $d(x)$ is deaths among agents who were aged $x$ at earlier census[9].

\section{b. $\quad$ Survival ratio method}

The secondapproach to estimate net migration for the period between two censuses involve the use of survivorship probabilities. The basic information required is the number of agents classified by age and sex as enumerated in each society at two successive censuses and a set of survival ratios which can be applied to the population at the first census in order to drive an estimate of the number of agents expected to survive to the second census. The difference between the enumerated population at second census and the expected population is the estimate of net migration. The survival ratio method has two methods(i) The forward survival ratio method :

$$
\text { Net } M^{\prime}(x)=p_{x+n, t+n}-S \cdot p_{x, t}
$$

(ii) The reverse survival ratio method:

$$
\text { Net } M^{\prime \prime}(x)=(1 / S) \cdot p_{x+n, t+n}-p_{x, t}
$$

Where $M^{\prime}(x)$ is the net migration of survivors among agents aged $x$ at the first census in a given society (they will be aged $x+n$ at second census), $p_{x, t}$ is the population aged $x$ in that society at the first census, $p_{x+n, t+n}$ is the population aged $x+n$ years in the same society at second census separated from the first census by n years, and $S$ is the survival ratio[9].

The survival ratio used to estimate net migration can be calculated using life table survival ratios (LTSR) describing the average mortality conditions of intercensal period for particular society. If the intercensal period is ten years and population is classified by five-year age groups, forward survival ratio can be given by formula:

$$
{ }_{10} \mathrm{~S}_{\mathrm{x}}={ }_{5} \mathrm{~L}_{\mathrm{x}+10} /{ }_{5} \mathrm{~L}_{\mathrm{x}}
$$

Where $x=0,5,10 \ldots \ldots, 10 S_{x}$ is the 10 -year survival ratio from age group $(x$ to $x+4)$ to age group $(x+10$ to $x+14)$ and ${ }_{5} \mathrm{~L}_{\mathrm{x}}$ are the number of agents in age group $\mathrm{x}+10$ to $x+14$ and $x$ to $x+4$.

\section{METRICS FOR MEASURING POPULATION DYNAMICS}

The Agent-based computing model is implemented in object oriented programming languages as it has advantage of reusability and modularity. Both agents and environment is implemented as objects. Each object is having its data and procedure. Object oriented metrics are used to measure properties of object oriented designs so that systems have minimal faults. These measures allows the designers to access the software early in the process, making changes that will reduce complexity and improve the capability of the product.Measurement enables to improve the software process, assist in the planning, tracking the control of a design. A good software engineer uses measurements to assess the quality of the analysis and 


\section{International Journal of Advanced Research in Computer and Communication Engineering} Vol. 4, Issue 3, March 2015

design model, the source code, the test cases, etc. Metrics are categorized into two groups: -- Project based metrics and design based metrics.

\section{A. $\quad$ Project Based Metrics}

Project based metrics consist of three metrics that are: --

1) Process Metrics: -- Processes are said to be the software related activities that are used to measure the status and progress of the system design. It is used to predict future effects. A process is always related with a time scale i.e. implicit or explicit [5]. The timing can be explicit when an activity must be finished in specific date, and it is implicit when one activity must be finished before another can begin. Examples of process related metrics are - Total development time,

- Development time in each process and sub process,

- Time spent to modify models from previous processes,

- $\quad$ Time spent in all kinds of subprocess, such as use case specification, objectspecification, use case design, block design, block testing and use case testing foreach particular object,

- $\quad$ Number of different kind of fault found during reviews,

- Number of change proposals on previous models,

- Cost for quality assurance,

- $\quad$ Cost for introducing new development process and tools.

2) Product Metrics: -- Product metrics control the quality of the software product. These metrics areapplied to incomplete software products in order to measure their complexity and topredict properties of the final product [5]. Some quality criteria to control quality are: --

- Number, width and height of the inheritances hierarchies,

- Number of classes inheriting a specific operation, - Number of classes that a specific class is dependent on,

- Number of classes that are dependent on a specific class,

- Number of direct users of a class or operation.

3) Resource Metrics: -- Resources are entities required by a process activity. The resources are the input for software production [5]. Thus, personnel, materials, tools, and methods are candidates for measurement. Resources have internal and external attributes: --

- Internal attributes of a product, process or resource are those that can be measured by examining the product, process, or resource itself.

- External attributes of a product, process or resource are those that can be measured onlywith respect to how the produced process or resource, relates to its environment. Here, thebehavior of the process, product or resource is important,.

- $\quad$ rather than the entity itself.

B. Design based metrics

Design based metrics are further divided as:-

1) Traditional metrics: -- Traditional metrics are applied for the measurement of software complexity of structured systems [5]. It consist of three metrics: -McCabe Cyclomatic Complexity (CC), source lines of code (SLOC), Comment Percentage (CP)

2) Chidamber Kemerer Metrics Model: -- C.K. metrics is the most well known measurement metrics used now. This metric offers informative insight into whether developers are following object oriented principles in their design [5]. They claim that using several of their metrics collectively helps managers and designers to make better design decision. They proposed six metrics: -- Weighted method per class (WMC), Depth of Inheritance Tree (DIT), Number of Children (NOC), Coupling between Objects (CBO), Response for a Class (RFC), Lack of cohesion in methods (LCOM)

3) MOOD Metrics Model: -- It is called as Metrics for Object Oriented Design. In MOOD metrics model, two main features are used in every metrics; they are methods and attributes. Methods are used to perform operations of several kinds such as obtaining or modifying the status of objects [5]. Attributes are used to represent the status of each object in the system. Each feature (methods and attributes) is either visible or hidden from a given class. It consists of metrics as: -- Encapsulation, Inheritance, polymorphism, Coupling.

\section{CONCLUSION}

The change in population of humans occurs due natality, mortality, and migration. These act as key elements of population change. This change in human population is called population dynamics. To simulate the human society artificial agent modeling technique is used which consist of agents as citizens of agent society as human population has humans as citizens of its population. The first model that simulated the human society is sugarscape model. As the humans grow, die and migrate in their society, similarly agents do in their society. There are metrics direct and indirect that are used to measure rate of migration to and from an society. Moreover certain metrics are used to measure the population dynamics: product and process metrics. These metrics are essential to know the amount of transition in artificial agent societies and society is simulated via them.

\section{REFERENCES}

[1] G. M. L. S. D. Rosaci, "Cloning mechanism to improve agent performances," Italy, Preprint submitted to Elsevier, 2013.

[2] J. R. Weeks, Population, Introduction to concepts and issues, tenth Edition ed..

[3] R. A. Joshua M. Epstein, Growing Artificial Societies, Social Science from the bottom up.

[4] "Population Dynamics in the context of the Post-2015 Development Agenda," February 2013.

[5] M. Sarker, "An overview of Object Oriented Design Metrics," Master Thesis, Department of Computer Science, Umea University, Sweden, June 23, 2005.

[6] J. R. Meyer. General Entomology. [Online]. http://www.cals.ncsu.edu/course/ent425/library/tutorials/ecology/popn_dyn.html

[7] D. L. B. M. F. R. David E. Bloom. Annenberg Learner. [Online]. http://www.learner.org/courses/envsci/unit/text.php?unit=5\&secNum=0

[8] Merriam Webster. [Online]. http://www.merriamwebster.com/dictionary/population\%20dynamics

[9] "Indirect Measures of Net Internal Migration," in Methods of measuring Internal Migration. United Nations, 1970, ch. 2, pp. 24-36.

[10] D. S. D. a. D. W. Paul R. Ehrlich. (1988) stanford university. [Online]. https://web.stanford.edu/group /stanfordbirds/tex t/essays /Populatio n_Dynamics.html 